\title{
High-performance organic semiconductors for thin-film transistors based on 2,6-bis(2-thienylvinyl)anthracene $\dagger$
}

\author{
Myoung-Chul Um, ${ }^{a}$ Junhyuk Jang, ${ }^{b}$ Jihoon Kang, ${ }^{a}$ Jung-Pyo Hong, ${ }^{a}$ Do Yeung Yoon, ${ }^{a}$ \\ Seong Hoon Lee, ${ }^{a}$ Jang-Joo Kim ${ }^{* b}$ and Jong-In Hong ${ }^{* a}$
}

\author{
Received 21st December 2007, Accepted 26th February 2008 \\ First published as an Advance Article on the web 20th March 2008 \\ DOI: $10.1039 / \mathrm{b} 719738 \mathrm{a}$
}

We have synthesized two novel organic semiconductors, which have a symmetrically substituted thienylvinylene anthracene backbone. They show good electrical performances on $\mathrm{SiO}_{2} / \mathrm{Si}$, with high field-effect mobilities of up to $0.4 \mathrm{~cm}^{2} \mathrm{~V}^{-1} \mathrm{~s}^{-1}$, and can easily be synthesized in large quantities. In addition, the high mobility of such semiconductors can be achieved at low substrate deposition temperatures.

\section{Introduction}

In the past few decades, acene and thiophene oligomers have been extensively studied for use as organic semiconductors in devices such as field-effect transistors (FETs), ${ }^{1-3}$ organic lightemitting diodes (OLEDs), ${ }^{4}$ photovoltaic cells, ${ }^{5}$ sensors,${ }^{6}$ and radio frequency identification (RF-ID) tags. ${ }^{7}$ So far, pentacene has shown remarkable properties as the best thin-film material with very high field-effect mobilities $\left(0.3-0.7 \mathrm{~cm}^{2} \mathrm{~V}^{-1} \mathrm{~s}^{-1}\right.$ on a $\mathrm{Si} / \mathrm{SiO}_{2}$ substrate, ${ }^{8} 1.5 \mathrm{~cm}^{2} \mathrm{~V}^{-1} \mathrm{~s}^{-1}$ on a chemically modified $\mathrm{Si} / \mathrm{SiO}_{2}$ substrate, ${ }^{9}$ and $3.0 \mathrm{~cm}^{2} \mathrm{~V}^{-1} \mathrm{~s}^{-1}$ on a modified alumina substrate $)^{10}$ and rubrene as the best single-crystal material $\left(15.4 \mathrm{~cm}^{2} \mathrm{~V}^{-1} \mathrm{~s}^{-1}\right) .{ }^{11}$ However, pentacene-based devices have poor air stability and rapid device-performance degradation. ${ }^{12}$ Therefore, environmentally stable, organic semiconducting materials with high mobilities and on : off current ratios that can be deposited at low substrate temperatures are still needed.

Very recently, several groups have developed semiconductors with high stability and conductivity by choosing conjugated vinylene-based oligomers. ${ }^{13}$ In fact, the presence of a double bond of a defined configuration (i) reduces the overall aromatic character of the planar structures and hence increases the $\pi$-electron localization, and (ii) restricts the rotational freedom inherent to thiophenes, ${ }^{14}$ which increases the energy-band gap. ${ }^{15}$ The introduction of a vinylene unit into oligomeric structures is a well-known method for forming coplanar molecules with an extended $\pi$-conjugated length, which should help to maximize the organization of the molecules in thin films. The devices derived from oligothiophenes end-capped with a styryl unit not only show very high field-effect mobilities (up to $0.1 \mathrm{~cm}^{2} \mathrm{~V}^{-1} \mathrm{~s}^{-1}$ ) and on : off ratios (up to $10^{5}$ ) but are also found to be exceptionally long-lived and stable in continuous operation under atmospheric conditions. ${ }^{13 a}$ In this study, we report the

${ }^{a}$ Department of Chemistry, College of Natural Sciences, Seoul National University, Seoul 151-747, Korea. E-mail: jihong@snu.ac.kr; Fax: +82-2-889-1568; Tel: +82-2-880-6682

${ }^{b}$ Department of Materials Science and Engineering, Seoul National University, Seoul 151-744, Korea. E-mail: jjkim@snu.ac.kr; Fax: +82-2885-9671; Tel: $+82-2-880-7085$

$\dagger$ Electronic supplementary information (ESI) available: More detailed device data, including CV, AFM and POM. See DOI: 10.1039/b719738a

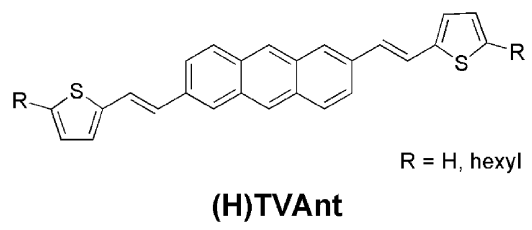

Fig. 1 Structures of $(H)$ TVAnt $(\mathrm{R}=\mathrm{H}$; TVAnt, $\mathrm{R}=$ hexyl; HTVAnt).

synthesis of 2,6-bis(2-thienylvinyl)anthracene (TVAnt) and hexyl-substituted HTVAnt (Fig. 1), ${ }^{13 b}$ and their excellent field-effect mobilities (up to $0.4 \mathrm{~cm}^{2} \mathrm{~V}^{-1} \mathrm{~s}^{-1}$ ) and high on : off ratio (up to $10^{5}-10^{6}$ ) of their TFT devices. In particular, TVAnt has 7 times higher mobility in comparison with dithiophen-2'yl-2,6-anthracene (DTAnt) without vinyl groups under similar conditions. ${ }^{16}$ Furthermore, TVAnt and HTVAnt exhibit high thermal stability when compared with pentacene-based organic semiconductors as determined by thermal gravimetric analysis (TGA).

\section{Experimental}

\section{General}

${ }^{1} \mathrm{H}$ and ${ }^{13} \mathrm{C}$ NMR spectra were recorded using an Advance 300 $\mathrm{MHz}$ Bruker spectrometer in $\mathrm{CDCl}_{3} .{ }^{1} \mathrm{H}$ NMR chemical shifts in $\mathrm{CDCl}_{3}$ were referenced to $\mathrm{CHCl}_{3}(7.27 \mathrm{ppm})$, and ${ }^{13} \mathrm{C} \mathrm{NMR}$ chemical shifts in $\mathrm{CDCl}_{3}$ were reported relative to $\mathrm{CHCl}_{3}$ (77.23 ppm).

\section{Physical measurement}

TGA analyses were performed on a TGA Q50 TA instrument at $10{ }^{\circ} \mathrm{C} \mathrm{min}^{-1}$ under a nitrogen atmosphere. DSC analyses were performed on a DSC2910 TA instrument at $10{ }^{\circ} \mathrm{C} \mathrm{min}^{-1}$ under nitrogen flow. UV-vis absorption spectra were recorded on a Beckman Coulter DU 800 spectrophotometer using $2.5 \mathrm{~cm}$ path-length quartz cells. For solid-state measurements, oligomers were thermally evaporated in a vacuum chamber on quartz plates to form $300 \AA$ thick films at the deposition rate of $0.5 \AA \mathrm{s}^{-1}$. XRD analyses were carried out at room temperature with a Mac Science (M18XHF-22) diffraction meter using $\mathrm{CuK} \alpha$ radiation as the $\mathrm{X}$-ray source at $50 \mathrm{kV}$ and $100 \mathrm{~mA}$. Data were 
collected in the conventional $\theta-2 \theta$ configuration $\left(2.5-30^{\circ}\right)$ from thin films thermally evaporated in a vacuum chamber on $\mathrm{SiO}_{2} /$ Si substrates at $0.5 \AA \mathrm{s}^{-1}$ for $300 \AA$. AFM images of the same vacuum-deposited thin films were taken using a PSIA XE-100 advanced scanning microscope. The voltammetric apparatus used was a $\mathrm{CH}$ Instruments model $700 \mathrm{C}$ electrochemical workstation. Cyclic voltammograms (CVs) were obtained at room temperature in a three-electrode cell with a working electrode $(\mathrm{Au})$, a reference electrode $(\mathrm{Ag} / \mathrm{AgCl})$, and a counter electrode $(\mathrm{Pt})$ in dichlorobenzene containing tetrabutylammonium hexafluorophosphate $\left(\mathrm{Bu}_{4} \mathrm{~N}^{+} \mathrm{PF}_{6}{ }^{-}, 0.1 \mathrm{M}\right)$ as a supporting electrolyte at a scan rate of $100 \mathrm{mV} \mathrm{s}^{-1}$. All the potentials were calibrated with the standard ferrocene/ferrocenium redox couple $(E=+0.41 \mathrm{~V}$ measured) .

\section{Fabrication of TFT devices}

The field-effect measurements were carried out using top-contact FETs. TFT devices with a channel length $(L)$ of $50 \mu \mathrm{m}$ and a channel width $(W)$ of $500 \mu \mathrm{m}$ were fabricated on thermally oxidized, highly n-doped silicon substrates. The $\mathrm{SiO}_{2}$ gate dielectric was $300 \mathrm{~nm}$ thick. The organic semiconductor $(300 \AA)$ was evaporated $\left(0.1 \AA \mathrm{s}^{-1}\right.$ at $1 \times 10^{-6}$ torr $)$ onto a non-pretreated or OTS-pretreated oxide surface. Gold source and drain electrodes were evaporated on top of the films through a shadow mask. All measurements were performed at room temperature using a 4155C Agilent semiconductor parameter analyzer, and mobilities $(\mu)$ were calculated in the saturation regime by using the relationship: $\mu_{\text {sat }}=\left(2 I_{\mathrm{DS}} L\right) /\left(W C\left(V_{\mathrm{g}}-V_{\mathrm{th}}\right)^{2}\right)$, where $I_{\mathrm{DS}}$ is the source-drain saturation current; $C\left(1.18 \times 10^{-8} \mathrm{~F}\right)$ the oxide capacitance, $V_{\mathrm{g}}$ the gate voltage, and $V_{\mathrm{th}}$ the threshold voltage.

\section{Synthesis}

2,6-Bis(chloromethyl)anthraquinone. A mixture of 2.6-dimethylanthraquinone $(3.8 \mathrm{~g}, 16.09 \mathrm{mmol}), \mathrm{SO}_{2} \mathrm{Cl}_{2}(50 \mathrm{~mL})$, and 2,2'-azobis(2-methylpropionitrile) (0.16 g, $0.96 \mathrm{mmol})$ was refluxed for $24 \mathrm{~h}$. Excess $\mathrm{SO}_{2} \mathrm{Cl}_{2}$ was removed by distillation in vacuo. The solid residue was collected by filtration, washed several times with petroleum ether, dried, and recrystallized from DMF to yield $3.8 \mathrm{~g} \mathrm{(78 \% )} \mathrm{of} \mathrm{2,6-bis(chloromethyl)anthra-}$ quinone. ${ }^{1} \mathrm{H}$ NMR (300 MHz, $\left.\mathrm{CDCl}_{3}\right): \delta 8.41(\mathrm{~m}, 4 \mathrm{H}), 7.98$ $(\mathrm{s}, 2 \mathrm{H}), 5.00(\mathrm{~s}, 4 \mathrm{H})$. High-resolution mass spectrometry (HRMS): calcd for $\mathrm{C}_{16} \mathrm{H}_{10} \mathrm{Cl}_{2} \mathrm{O}_{2}$ 304.0057. Found: 304.0034 .

2,6-Bis(hydroxymethyl)anthraquinone. A suspension of 2,6bis(chloromethyl)anthraquinone $(3.5 \mathrm{~g}, 11.47 \mathrm{mmol})$ in $300 \mathrm{~mL}$ of water and $400 \mathrm{~mL}$ of DMSO was refluxed with vigorous stirring. Upon heating for $4 \mathrm{~h}$, a clear solution was obtained. The reaction mixture was refluxed for $38 \mathrm{~h}$ and then cooled to room temperature. The crystalline product was collected by filtration and recrystallized from DMF to give $3.0 \mathrm{~g}(98 \%)$ of 2,6-bis(hydroxymethyl)anthraquinone. ${ }^{1} \mathrm{H}$ NMR $(300 \mathrm{MHz}$, DMSO): $\delta 8.17(\mathrm{~m}, 4 \mathrm{H}), 7.85(\mathrm{~d}, 2 \mathrm{H}, J=10.7 \mathrm{~Hz}), 5.57(\mathrm{~s}, 2 \mathrm{H})$, $4.70(\mathrm{~s}, 4 \mathrm{H})$. High-resolution mass spectrometry (HRMS): calcd for $\mathrm{C}_{16} \mathrm{H}_{12} \mathrm{O}_{4}$ 268.0735. Found: 268.0749.

2,6-Bis(dihydroxymethyl)anthracene. To a solution of 2,6-bis(hydroxymethyl)anthraquinone (2.8 g $10.43 \mathrm{mmol})$ in concentrated ammonium hydroxide $(70 \mathrm{~mL})$ was added zinc power $(6.0 \mathrm{~g})$. The reaction was refluxed overnight. The insoluble material was removed by filtration and washed with hot DMSO. The solution was precipitated in $200 \mathrm{~mL}$ of $1 \mathrm{~N} \mathrm{HCl}$. The product was collected by filtration to give $1.86 \mathrm{~g}(75 \%)$ of 2,6-bis(dihydroxymethyl)anthracene. ' $\mathrm{H}$ NMR (300 $\mathrm{MHz}$, DMSO): $\delta 8.49$ (s, $2 \mathrm{H}), 8.04(\mathrm{~d}, 2 \mathrm{H}, \mathrm{J}=8.7 \mathrm{~Hz}), 7.94(\mathrm{~s}, 2 \mathrm{H})$, $7.46(\mathrm{~d}, 2 \mathrm{H}, \mathrm{J}=8.7 \mathrm{~Hz}), 5.40(\mathrm{t}, 2 \mathrm{H}, \mathrm{J}=5.6 \mathrm{~Hz}), 4.69(\mathrm{~d}, 4 \mathrm{H}$, $\mathrm{J}=5.6 \mathrm{~Hz}$ ). High-resolution mass spectrometry (HRMS): Calcd. for $\mathrm{C}_{16} \mathrm{H}_{14} \mathrm{O}_{2}$ 238.0994. Found: 238.1003 .

2,6-Bis(dibromomethyl)anthracene. Phosphorus tribromide $(4.4 \mathrm{~g}, 16.30 \mathrm{mmol})$ was added dropwise to a suspension of 2,6-bis(dihydroxymethyl)anthracene $(1.5 \mathrm{~g}, 6.29 \mathrm{mmol})$ in DMF $(30 \mathrm{~mL})$ at $0{ }^{\circ} \mathrm{C}$. Upon formation of a yellow precipitate, the mixture was warmed to room temperature and stirred for $4 \mathrm{~h}$. The solids were collected by filtration and were washed with water and hexane to give rise to a yellow solid (2.2 g, 98\%) of 2,6-bis (dibromomethyl)anthracene. The product was further purified by recrystallization from DMF. ${ }^{1} \mathrm{H}$ NMR (400 MHz, DMSO): $\delta 8.56(\mathrm{~s}, 2 \mathrm{H}), 8.15(\mathrm{~s}, 2 \mathrm{H}), 8.12(\mathrm{~d}, 2 \mathrm{H}, J=11.5 \mathrm{~Hz}), 7.56$ $(\mathrm{d}, 2 \mathrm{H}, J=8.7 \mathrm{~Hz}), 4.93(\mathrm{~s}, 4 \mathrm{H})$. High-resolution mass spectrometry (HRMS): calcd for $\mathrm{C}_{16} \mathrm{H}_{12} \mathrm{Br}_{2} 361.9306$. Found: 361.9277.

2,6-Bis(diethylphosphorylmethyl)anthracene. 2,6-Bis(dibromomethyl)anthracene ( $2.2 \mathrm{~g}, 6.04 \mathrm{mmol})$ was added to triethylphosphite $(50 \mathrm{~mL})$, and the resulting solution was refluxed for $12 \mathrm{~h}$. The solvent was removed in vacuo, and the residue was purified by column chromatography on silica gel using ethyl acetatedichloromethane $(2: 1)$ as the eluent. Yield $(90 \%)$. ${ }^{1} \mathrm{H}$ NMR $\left(300 \mathrm{MHz}, \mathrm{CDCl}_{3}\right): \delta 8.35(\mathrm{~s}, 2 \mathrm{H}), 7.97(\mathrm{~d}, 2 \mathrm{H}, J=8.7 \mathrm{~Hz})$, $7.90(\mathrm{~s}, 2 \mathrm{H}), 7.46(\mathrm{~d}, 2 \mathrm{H}, J=8.7 \mathrm{~Hz}), 4.03(\mathrm{~m}, 8 \mathrm{H}), 3.39$ $(\mathrm{d}, 4 \mathrm{H}, J=21.8 \mathrm{~Hz}), 1.26(\mathrm{t}, 12 \mathrm{H}, J=7.0 \mathrm{~Hz}) .{ }^{13} \mathrm{C}$ NMR $\left(300 \mathrm{MHz}, \mathrm{CDCl}_{3}\right.$ ): $131.54,130.83,128.75,128.61,128.39$, 127. 84, 125. 67, (62.26, 62.16), (35.10, 33.27), (16.44, 16.30). MS (EI) $m / z:\left(\mathrm{M}^{+}\right)$calcd for $\mathrm{C}_{24} \mathrm{H}_{32} \mathrm{O}_{6} \mathrm{P}_{2} 478.16$; found 478 .

2,6-Bis(2-thienylvinyl)anthracene. LDA (1.5 M in cyclohexane, $2.9 \mathrm{~mL}, 5.22 \mathrm{mmol}$ ) was added dropwise to a stirred solution of 2,6-bis(diethylphosphorylmethyl)anthracene $(1.0 \mathrm{~g}, 2.09 \mathrm{mmol})$ in anhydrous THF $(50 \mathrm{~mL})$ at $-78{ }^{\circ} \mathrm{C}$ under nitrogen. The mixture was stirred for $1 \mathrm{~h}$ and then thiophene-2-carbaldehyde $(0.58 \mathrm{~g}, 5.22 \mathrm{mmol})$ in THF $(10 \mathrm{~mL})$ was added dropwise over a period of $10 \mathrm{~min}$. After the mixture was stirred for $2 \mathrm{~h}$ at $-78{ }^{\circ} \mathrm{C}$ and for $12 \mathrm{~h}$ at room temperature, $5 \mathrm{~mL}$ of water was added and the solvent was evaporated. The residue was washed with water and $\mathrm{MeOH}$. The desired product was separated by sublimation. High-resolution mass spectrometry (HRMS): calcd for $\mathrm{C}_{26} \mathrm{H}_{18} \mathrm{~S}_{2}$ 394.0850. Found: 394.0852. Anal. calcd: C, 79.15; $\mathrm{H}, 4.60$; S, 16.25; found: C, 79.24; H, 4.56; S, 16.21\%.

2,6-Bis[2-(5-hexylthienyl)vinyl]anthracene. LDA (1.5 M in cyclohexane, $3.2 \mathrm{~mL}, 5.75 \mathrm{mmol}$ ) was added dropwise to a stirred solution of 2,6-bis(diethylphosphorylmethyl)anthracene (1.2 g, $2.50 \mathrm{mmol})$ in anhydrous THF $(50 \mathrm{~mL})$ at $-78{ }^{\circ} \mathrm{C}$ under nitrogen. The mixture was stirred for $1 \mathrm{~h}$ and then 5-hexylthiophene-2-carbaldehyde $(1.47 \mathrm{~g}, 7.50 \mathrm{mmol})$ in THF $(20 \mathrm{~mL})$ was added dropwise over a period of $10 \mathrm{~min}$. After the mixture was stirred for $2 \mathrm{~h}$ at $-78^{\circ} \mathrm{C}$ and for $12 \mathrm{~h}$ at room temperature, 
$5 \mathrm{~mL}$ of water was added and the solvent was evaporated. The residue was washed with water and $\mathrm{MeOH}$. The desired product was separated by sublimation. High-resolution mass spectrometry (HRMS): calcd for $\mathrm{C}_{38} \mathrm{H}_{42} \mathrm{~S}_{2}$ 562.2728. Found: 562.2728. Anal. calcd: C, 81.09; H, 7.52; S, 11.39; found: C, 80.99 ; H, 7.03; S, $11.63 \%$.

\section{Results and discussion}

The synthesis of $(\mathrm{H})$ TVAnt starts with the preparation of 2,6dimethylanthraquinone from the Diels-Alder reaction of isoprene and $p$-benzoquinone. ${ }^{17}$ Treatment of 2,6-dimethylanthraquinone with an excess of sulfuryl chloride in the presence of a catalytic amount of 2,2'-azobis(2-methylpropionitrile) (AIBN) at refluxing temperature afforded 2,6-bis(chloromethyl)anthraquinone, which is the key intermediate for the preparation of anthracene derivatives. Refluxing 2,6-bis(chloromethyl)anthraquinone in a mixture of water and $\mathrm{Me}_{2} \mathrm{SO}$ gave the alcohol derivative, which was then reduced with $\mathrm{Zn}$ and $\mathrm{NH}_{4} \mathrm{OH}$ to give 2,6-bis(hydroxymethyl)anthracene in good yield. Treatment of the resulting diol with phosphorus tribromide in DMF at room temperature gave 2,6-bis(bromomethyl)anthracene. One of the precursors of the Horner-Emmons olefination, 2,6-bis(diethylphosphorylmethyl)anthracene, was prepared by reaction of the dibromide with triethylphosphite. The organization of oligomers in thin films can be maximized by the introduction of vinylene units. The semiconducting materials were synthesized by the HornerEmmons coupling reactions between the phosphonate and aldehyde derivatives, as shown in Scheme 1. The Horner-Emmons coupling reaction is well known for forming all-trans configurations. ${ }^{18}$ TVAnt and HTVAnt, purified by sublimation, were identified by high-resolution mass spectrometry and elemental analyses, while their thermal stability was investigated using thermal gravimetric analysis (TGA). Thermal decomposition temperatures were $336{ }^{\circ} \mathrm{C}$ for TVAnt and $376{ }^{\circ} \mathrm{C}$ for HTVAnt, while, by contrast, pentacene began to decompose at $260{ }^{\circ} \mathrm{C}$ (due to sublimation), confirming the high thermal stability of (H)TVAnt compounds (Fig. 2).

Differential scanning calorimetry (DSC) measurements for HTVAnt showed phase transitions at $19{ }^{\circ} \mathrm{C}\left(10.1 \mathrm{~kJ} \mathrm{~mol}^{-1}\right)$, $100{ }^{\circ} \mathrm{C}\left(4.5 \mathrm{~kJ} \mathrm{~mol}^{-1}\right), 255^{\circ} \mathrm{C}\left(30.5 \mathrm{~kJ} \mathrm{~mol}^{-1}\right.$, melting $), 289^{\circ} \mathrm{C}$, and $295^{\circ} \mathrm{C}$, while an isotropic phase transition was observed

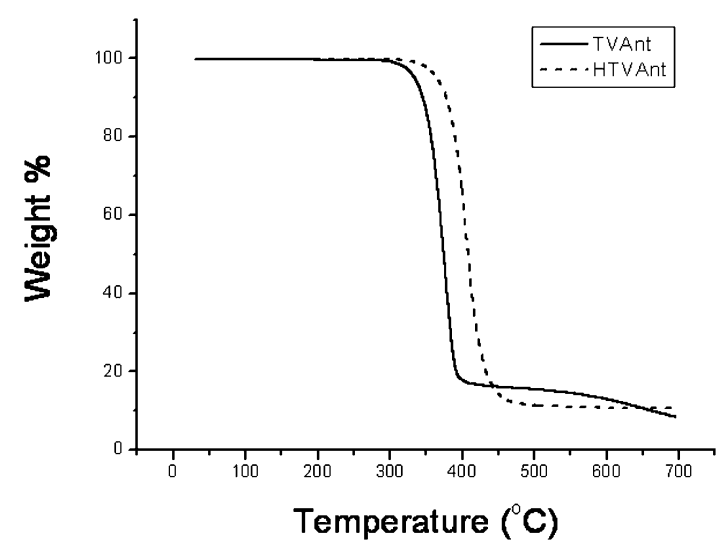

Fig. 2 Thermal gravimetric analysis (TGA) of TVAnt and HTVAnt.

after $295{ }^{\circ} \mathrm{C}$ (Fig. 3a). A typical focal conic texture and a fan shaped texture were observed at $265^{\circ} \mathrm{C}$, indicating that HTVAnt exhibits a highly ordered, liquid crystalline structure such as a smectic phase. The solid-solid phase transitions below $255^{\circ} \mathrm{C}$ have not been identified yet.

The UV-vis spectrum of a dilute solution of TVAnt in toluene showed absorption peaks at 426, 400, 345 and $328 \mathrm{~nm}$, which were similar to the spectra of HTVAnt (Fig. 4). The long-wavelength absorptions in the films of the two compounds showed slight red-shifts compared to those in solutions. Interestingly, in the PL spectra, the differences in emission maxima between the solution and film states of TVAnt and HTVAnt were 100 and $70 \mathrm{~nm}$, respectively, indicating the presence of extremely strong intermolecular interactions in the film states. ${ }^{19}$

The UV-vis spectra of TVAnt and HTVAnt, as deposited thin films, showed long-wavelength absorption edges at 486 and 477 $\mathrm{nm}$, respectively, which corresponded to HOMO-LUMO energy gaps of 2.55 and $2.59 \mathrm{eV}$, and which were significantly higher than that of pentacene $(2.2 \mathrm{eV}) .{ }^{20}$ Further insight into the electronic properties of these compounds was provided by cyclic voltammetry $(\mathrm{CV})$. CV measurements of TVAnt and HTVAnt in $0.1 \mathrm{M} \mathrm{Bu}_{4} \mathrm{~N}^{+} \mathrm{PF}_{6}{ }^{-}$-dichlorobenzene solution showed an irreversible oxidation peak. The onset potentials of oxidation were located at $0.62 \mathrm{eV}$ and $0.4 \mathrm{eV}$ vs. ferrocene (FOC). Regarding the energy level of the FOC/ferrocenium reference $(-4.8 \mathrm{eV})$,<smiles>Cc1ccc2c(c1)C(=O)c1ccc(C)cc1C2=O</smiles>
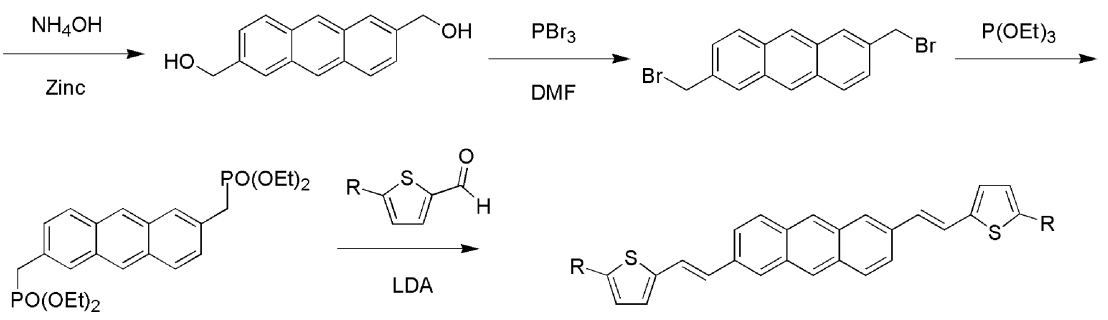

Scheme 1 Synthesis of 2,6-bis[2-(5-hexylthienyl)vinyl]anthracene. 

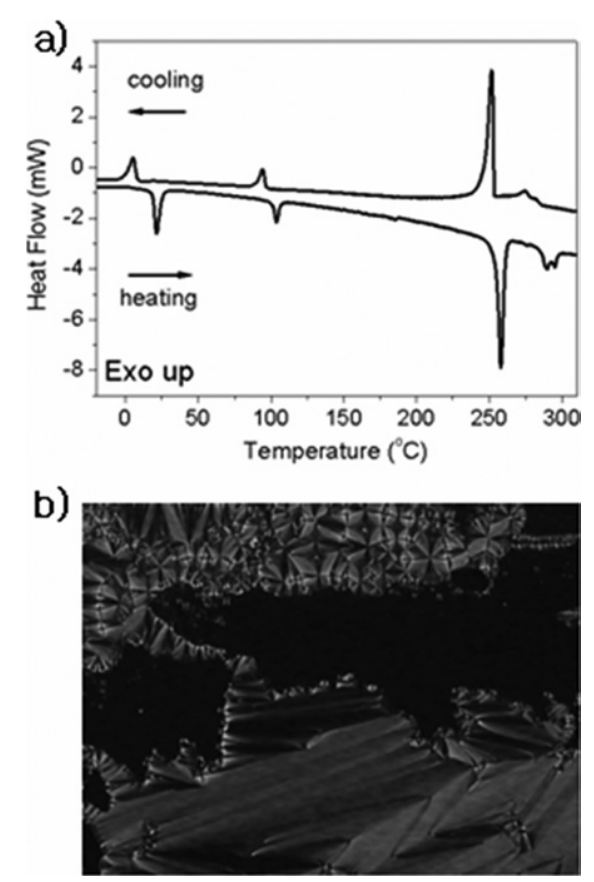

Fig. 3 (a) Differential scanning calorimetry of HTVAnt at a scanning rate of $10{ }^{\circ} \mathrm{C} \mathrm{min}-1$ for heating and cooling cycles. (b) Polarized optical micrograph of the HTVAnt phase at $266^{\circ} \mathrm{C}$.

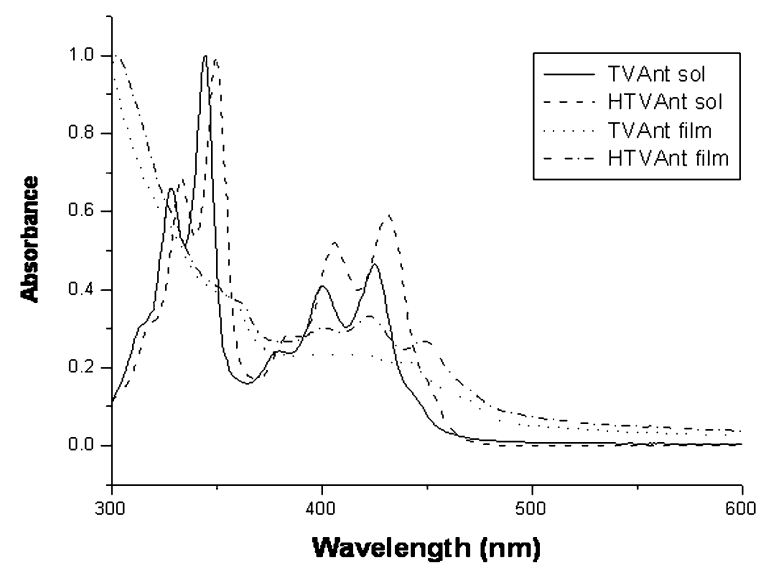

Fig. 4 UV-vis absorption spectra of TVAnt and HTVAnt.

the HOMO energy levels of TVAnt and HTVAnt were -5.42 and $-5.20 \mathrm{eV}$, respectively, which were lower than that of pentacene, thus indicating their high oxidative stability (Fig. S7†) ${ }^{21}$

The morphological characteristics were investigated by X-ray diffraction (XRD) (Fig. 5a and b). The thin-film XRD pattern of TVAnt displayed a primary diffraction peak at $2 \theta=4.34^{\circ}$ ( $d$-spacing $20.34 \AA$ ), with second-, third- and fourth-order diffraction peaks at $2 \theta=8.56^{\circ}, 12.70^{\circ}$ and $16.88^{\circ}$, respectively. The strong intensity of the X-ray diffraction peaks indicated the formation of lamellar ordering and crystallinity on the substrate. The $d$-spacing of TVAnt obtained from the first reflection peak was $20.34 \AA$, comparable to the molecular length obtained from the MM2 calculation (21.28 $\AA$ ). These spacings were consistent with the monomolecular layer thickness obtained by atomic force microscopy (AFM), as shown in
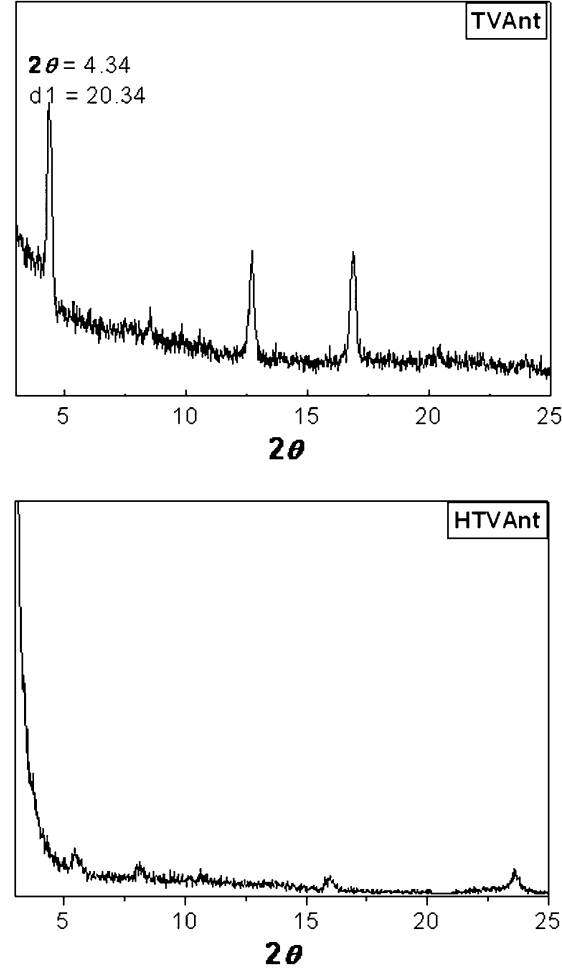

Fig. 5 XRD patterns of (a) TVAnt and (b) HTVAnt thin films vacuumdeposited on OTS-treated $\mathrm{SiO}_{2} / \mathrm{Si}$ at $T_{\text {sub }}=75^{\circ} \mathrm{C}$.
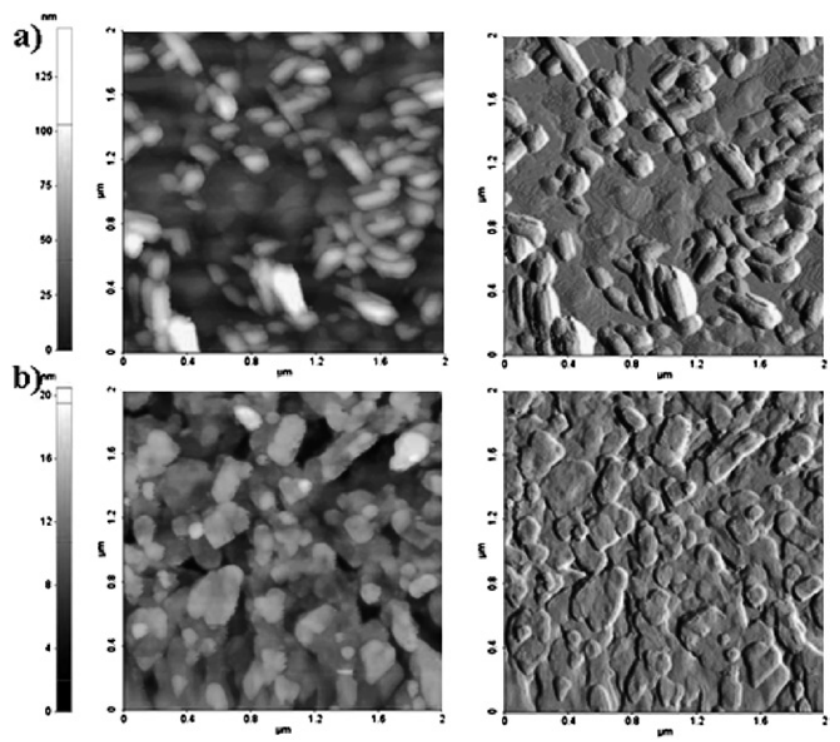

Fig. 6 Noncontact mode AFM (topogaphy and amplitude) image $(2 \times$ $2 \mu \mathrm{m}$ area) of TVAnt and HTVAnt at $75^{\circ} \mathrm{C}$ : (a) TVAnt, (b) HTVAnt.

Fig. 6 and Fig. S6, $\dagger$ which indicated near-perpendicular alignment of the molecules with respect to the substrate surface. On the other hand, the XRD results of HTVAnt films exhibited weaker reflection peaks than TVAnt with the second-order diffraction peak at $5.55^{\circ}$. The film had a rather strong first-order diffraction peak below $3^{\circ}$, which was hard to resolve because the incident X-ray was overlapped with the diffracted beam. The $d$-spacing of HTVAnt obtained from the (200) plane was 
$31.8 \times \AA$, corresponding to the first-order diffraction of $2.78^{\circ}$. The $d$-spacing was a little smaller than the molecular length obtained from the MM2 calculation ( $36.38 \AA$ ), which indicated that the molecules were inclined about $30^{\circ}$ from the normal to the layer. The weak intensity, especially in the higher-order peaks, indicated that the long range order of HTVAnt was not as good as that of TVAnt, suggesting a lower mobility for HTVAnt compared to that of TVAnt. This is also in agreement with the performance of the devices. When used as a channel semiconductor in organic thin-film transistors (OTFTs), HTVAnt displayed low FET mobility compared to TVAnt.

The OTFTs of TVAnt and HTVAnt were fabricated using top contact geometry with Au electrodes. Gold source and drain contacts $(50 \mathrm{~nm})$ were deposited onto the organic layer through a shadow mask. The channel length $(L)$ and width $(W)$ were 50 and $500 \mu \mathrm{m}$, respectively. Thin films of the two conjugated oligomers were formed by vacuum evaporation onto either untreated or octadecyltrichlorosilane (OTS)-coated $\mathrm{Si} / \mathrm{SiO}_{2}$ substrates at various temperatures $\left(T_{\text {sub }}=25{ }^{\circ} \mathrm{C}, 50{ }^{\circ} \mathrm{C}\right.$ and $\left.75{ }^{\circ} \mathrm{C}\right)$. All the OTFTs showed typical p-channel TFT characteristics.

Fig. 7 shows the drain current $\left(I_{\mathrm{DS}}\right)$ versus source-drain $\left(V_{\mathrm{DS}}\right)$, and transfer characteristics of TVAnt and HTVAnt TFTs grown at a substrate temperature $\left(T_{\text {sub }}\right)$ of $75^{\circ} \mathrm{C}$. From the electrical transfer characteristics, we extracted the following parameters for each device and summarized them in Table 1: the carrier mobility, on : off current ratio, threshold voltage, and subthreshold swing. The TVAnt devices fabricated under various
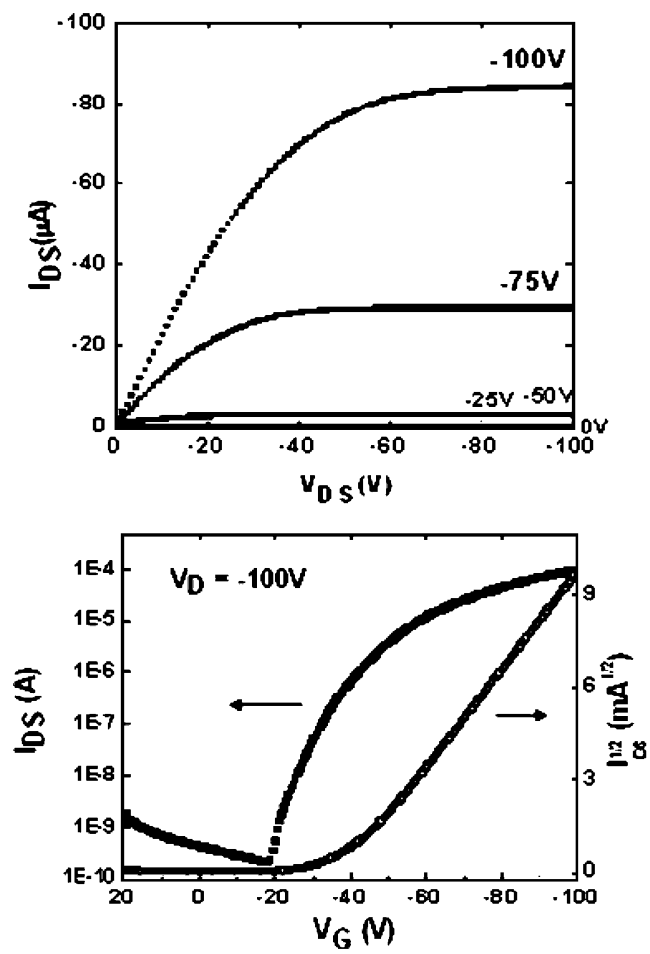

Fig. 7 Source-drain current $\left(I_{\mathrm{DS}}\right)$ versus source-drain voltage $\left(V_{\mathrm{DS}}\right)$ at various gate voltages $\left(V_{\mathrm{G}}\right)$ for a top-contact field-effect transistor using TVAnt deposited at $T_{\text {sub }}=75{ }^{\circ} \mathrm{C}$ on OTS-treated $\mathrm{SiO}_{2}$. The transfer characteristics in the saturation regime at a constant source-drain voltage $\left(V_{\mathrm{DS}}=-100 \mathrm{~V}\right)$ are also shown.
Table 1 Field-effect mobility $\left(\mu_{\mathrm{TFT}}\right)$, on : off current ratio $\left(I_{\mathrm{on}}: I_{\mathrm{off}}\right)$ and threshold voltage $\left(V_{\text {th }}\right)$ of TVAnt and HTVAnt vacuum-deposited on differently treated $\mathrm{SiO}_{2}$ surfaces and at different substrate temperatures $\left(T_{\text {sub }}\right)$

\begin{tabular}{llllll}
\hline & & \multicolumn{4}{c}{$\mu_{\mathrm{TFT}} / \mathrm{cm}^{2}$} \\
& & $T_{\text {sub }}$ & $\mathrm{V}^{-1} \mathrm{~s}^{-1}$ & $I_{\text {on }}: I_{\text {off }}$ & $V_{\text {th }} / \mathrm{V}$ \\
\hline \multirow{2}{*}{ TVAnt } & \multirow{2}{*}{ Bare } & 30 & 0.10 & $1.1 \times 10^{7}$ & -34 \\
& & 50 & 0.14 & $3.2 \times 10^{6}$ & -41 \\
& & 75 & 0.27 & $1.0 \times 10^{7}$ & -37 \\
& OTS & 30 & 0.18 & $4.6 \times 10^{6}$ & -31 \\
& & 50 & 0.27 & $8.1 \times 10^{6}$ & -36 \\
HTVAnt & & 75 & 0.44 & $4.8 \times 10^{5}$ & -39 \\
& \multirow{2}{*}{ Bare } & 30 & 0.02 & $1.3 \times 10^{5}$ & -31 \\
& & 50 & 0.03 & $5.2 \times 10^{5}$ & -29 \\
& & 75 & 0.07 & $4.4 \times 10^{7}$ & -28 \\
& OTS & 30 & 0.05 & $1.2 \times 10^{7}$ & -29 \\
& & 50 & 0.09 & $1.4 \times 10^{7}$ & -30 \\
& & 75 & 0.15 & $2.0 \times 10^{7}$ & -30 \\
\hline
\end{tabular}

conditions showed $\mu_{\mathrm{FET}}$ over $0.1 \mathrm{~cm}^{2} \mathrm{~V}^{-1} \mathrm{~s}^{-1}$ and an on : off ratio $>10^{5}-10^{7}$ under ambient conditions (Table 1). In particular, excellent FET characteristics, including $\mu_{\mathrm{FET}}$ higher than $0.44 \mathrm{~cm}^{2} \mathrm{~V}^{-1} \mathrm{~s}^{-1}$ (measured in the saturation regime), and an on : off ratio $>10^{5}$, were observed in TVAnt devices fabricated on the OTS-treated substrate at $T_{\text {sub }}=75^{\circ} \mathrm{C}$ (Fig. 7).

We found that the TFT performance depends critically on the side chain lengths of the active materials. Typically, the addition of an alkyl chain (hexyl) is expected to increase the structural order of the film and thus enhance the charge transport. ${ }^{16 a, 22}$ In our cases, however, the mobility of TVAnt was 3 times higher than that of HTVAnt. HTVAnt exhibited low FET mobility compared to TVAnt when used as a channel semiconductor in OTFTs. This is not surprising since charge transport in organic semiconductors is dominated by the crystal structure, and the less-ordered HTVAnt would not be expected to give high mobility. ${ }^{23}$

Fig. 6 shows AFM images of $30 \mathrm{~nm}$-thick films of the oligomers deposited on OTS-treated $\mathrm{SiO}_{2} / \mathrm{Si}$ at $75{ }^{\circ} \mathrm{C}$. At this temperature, the molecules became more ordered, and a network of interconnected grains was observed for the TVAnt sample. The AFM step heights for the lamellar structure of TVAnt grains (as obtained from the films deposited at $75^{\circ} \mathrm{C}$ ) corresponded well to the $d$-spacing obtained from the XRD results and the calculated molecular length.

\section{Conclusions}

We have synthesized two novel organic semiconductors, which have a symmetrically substituted thienylvinylene anthracene backbone. They show good electrical performances on $\mathrm{SiO}_{2} / \mathrm{Si}$, with high field-effect mobilities of up to $0.4 \mathrm{~cm}^{2} \mathrm{~V}^{-1} \mathrm{~s}^{-1}$, and can easily be synthesized in large quantities. In addition, the high mobility of such semiconductors can be achieved at low substrate deposition temperatures. TVAnt and HTVAnt show promising properties for applications in organic flexible electronics. We are currently investigating OTFT devices featuring TVAnt and HTVAnt to improve their performance, and the introduction of other alkyl chains to TVAnt for the synthesis of new soluble oligomers. 


\section{Acknowledgements}

This work was supported by grants (F0004030-2007-23, F0004071-2007-23) from the Information Display R\&D Center, one of the 21st Century Frontier R\&D Programs funded by the Ministry of Commerce, Industry, and Energy of the Korean Government, and Seoul R\&BD.

\section{References}

1 M. H. Yoon, S. A. DiBenedetto, A. Facchetti and T. J. Mark, J. Am. Chem. Soc., 2006, 128, 9598.

2 K. Takimiya, Y. Kunugi, Y. Konda, H. Ebata, Y. Toyoshima and T. Otsubo, J. Am. Chem. Soc., 2006, 128, 3044.

3 C. D. Dimitrakopoulos and R. L. Malenfant, Adv. Mater., 2002, 14, 99.

4 R. H. Friend, R. W. Gymer, A. B. Holmes, J. H. Burrouhes, R. N. Marks, C. Taliani, D. D. C. Bardley, D. A. DosSantos, J. L. Bredas, M. Logdlund and W. R. Salanek, Nature, 1999, 397, 121.

5 (a) C. J. Brabec, N. S. Sariciftci and J. C. Hummelen, Adv. Funct. Mater., 2001, 11, 15; (b) K. M. Coakley and M. D. McGhee, Chem. Mater., 2004, 16, 4533.

6 (a) B. Crone, A. Dodabalapur, Y.-Y. Lin, R. W. Filas, Z. Bao, A. LaDuca, R. Sarpeshkar, H. E. Katz and W. Li, Nature, 2000, 403, 521; (b) Y.-Y. Lin, A. Dodabalapur, R. Sarpeshkar, Z. Bao, W. Li, K. Baldwin, V. R. Raju and H. E. Katz, Appl. Phys. Lett., 1999, 74, 2714

7 (a) A. T. Brown, A. Pomp, C. M. Hart and D. M. Deleeuw, Science, 1995, 270, 972; (b) C. J. Drury, C. M. Mutsaers, C. M. Hart, M. Matters and D. M. de Leeuw, Appl. Phys. Lett., 1998, 73, 108.

8 D. J. Gundlach, Y. Y. Lin, T. N. Jackson, S. F. Nelson and D. G. Schlom, IEEE Electron Device Lett., 1997, $18,87$.

9 Y. Y. Lin, D. J. Gundlach, S. F. Nelson and T. N. Jackson, IEEE Electron Device Lett., 1997, 18, 606.

10 T. W. Kelly, Y. Lin, D. J. Gundlach, S. F. Nelson and T. N. Jackson, J. Phys. Chem. B, 2003, 107, 5877.

11 (a) V. C. Sundar, J. Zaumseil, V. Podzorov, E. Menard, R. L. Willett, T. Someya, M. E. Gershenson and J. A. Rogers, Science, 2004, 303,
1644; (b) V. Podzorov, S. E. Sysoev, E. Loginova, V. M. Pudalov and M. E. Gershenson, Appl. Phys. Lett., 2003, 83, 3504.

12 M. Yamada, I. Ikemoto and H. Kuroda, Bull. Chem. Soc. Jpn., 1988, 61, 1057.

13 (a) C. Videlot-Ackermann, J. Ackermann, H. Brisset, K. Kawamura, N. Yoshimoto, P. Raynal, A. EI Dassmi and F. Fages, J. Am. Chem. Soc., 2005, 127, 16346; (b) N. Drolet, J. F. Morin, N. Leclerc, S. Wakim, Y. Tao and M. Leclerc, Adv. Funct. Mater., 2005, 15, 1671; (c) T. C. Gorjanc, I. Levesque and M. D'lori, Appl. Phys. Lett., 2004, 84, 930; (d) H. Meng, F. Sun, M. B. Goldfinger, F. Gao, D. J. Londono, W. J. Marshal, G. S. Blackman, K. D. Dobbs and D. E. Keys, J. Am. Chem. Soc., 2006, 128, 9304; (e) H. Klauk, U. Zschieschang, R. T. Weitz, H. Mong, F. Sun, G. Nunes, D. E. Keys, C. R. Fincher and Z. Xiang, Adv. Mater., 2007, 19, 3882.

14 (a) G. Distefano, M. Da Colle, D. Jones, M. Zambianchi, L. Favvafetto and A. Modelli, J. Phys. Chem., 1993, 97, 3504; (b) E. Orti, P. M. Viruela, J. Sanchez-Marin and F. Tomas, J. Phys. Chem., 1995, 99, 4955.

15 J. Roncali, Chem. Rev., 1997, 97, 173.

16 (a) H. Meng, F. Sun, M. B. Goldfinger, G. D. Jaycox, Z. Li, W. J. Marshall and G. S. Blackman, J. Am. Chem. Soc., 2005, 127, 2406; (b) S. Ando, J. I. Nishida, E. Fujiwara, H. Tada, Y. Inoue, S. Tokito and Y. Yamshita, Chem. Mater., 2005, 17, 1261.

17 H. O. House, J. T. Holt and D. VanDerveer, J. Org. Chem., 1993, 58, 7516.

18 S. Pfeiffer and H. H. Horhold, Macromol. Chem. Phys., 1998, 200, 1870.

19 J. H. Park, D. S. Chung, J. W. Park, T. Ahn, H. Kong, Y. K. Jung, J. Lee, M. H. Yi, C. E. Park, S. K. Kwon and D. D. Shim, Org. Lett, 2007, 9, 2573.

20 I. G. Hill, J. Hwang, A. Kahn, C. Hung and J. E. McDermott, Appl. Phys. Lett., 2007, 90, 012109.

21 M. S. Liu, Y. Liu, R. C. Urian, H. Ma and A. K.-Y. Jen, J. Mater. Chem., 1999, 9, 2201.

22 M. Halik, H. Klauk, U. Zschieschang, G. Schmid, S. Ponomarenko, S. Kirchmeyer and W. Weber, Adv. Mater., 2003, 15, 917.

23 Y. Wu, Y. Li, S. Gardner and B. S. Ong, J. Am. Chem. Soc., 2005, $127,614$. 